\title{
Hemoglobin concentrations and RBC transfusion thresholds in patients with acute brain injury: an international survey
}

Rafael Badenes ${ }^{1}$, Mauro Oddo ${ }^{2}$, José I. Suarez ${ }^{3}$, Massimo Antonelli ${ }^{4}$, Jeffrey Lipmann,6, Giuseppe Citerio ${ }^{7,8}$ and Fabio Silvio Taccone $e^{9^{*}}$

\begin{abstract}
Background: The optimal hemoglobin $(\mathrm{Hb})$ threshold at which to initiate red blood cell (RBC) transfusion in patients with acute brain injury is unknown. The aim of this survey was to investigate RBC transfusion practices used with these patients.

Methods: We conducted a web-based survey within various societies of critical care medicine for intensive care unit (ICU) physicians who currently manage patients with primary acute brain injury.

Results: A total of 868 responses were obtained from around the world, half of which $(n=485)$ were from European centers; 204 (24\%) respondents had a specific certificate in neurocritical care, and most were specialists in anesthesiology or intensive care and had less than 15 years of practice experience. Four hundred sixty-six respondents (54\%) said they used an $\mathrm{Hb}$ threshold of 7-8 g/dl to initiate RBC transfusion after acute brain injury, although half of these respondents used a different threshold (closer to $9 \mathrm{~g} / \mathrm{dl}$ ) in patients with traumatic brain injury, subarachnoid hemorrhage, or ischemic stroke. Systemic and cerebral factors were reported as influencing the need for higher $\mathrm{Hb}$ thresholds. Most respondents agreed that a randomized clinical trial was needed to compare two different $\mathrm{Hb}$ thresholds for RBC transfusion, particularly in patients with traumatic brain injury, subarachnoid hemorrhage, and ischemic stroke.

Conclusions: The Hb threshold used for RBC transfusion after acute brain injury was less than $8 \mathrm{~g} / \mathrm{dl}$ in half of the ICU clinicians who responded to our survey. However, more than $50 \%$ of these physicians used higher $\mathrm{Hb}$ thresholds in certain conditions.
\end{abstract}

Keywords: Hemoglobin, Transfusion, Threshold, Brain injury, Outcome

\section{Background}

Anemia is highly prevalent during critical illness; $60 \%$ of patients admitted to intensive care units (ICUs) are considered anemic, and $20-30 \%$ have a first hemoglobin $\mathrm{Hb}$ concentration less than $9 \mathrm{~g} / \mathrm{dl}$ [1]. Moreover, after a 1-week ICU stay, up to $80 \%$ of patients will have $\mathrm{Hb}$ concentrations below this value [2]. Cohort studies have suggested a strong association between anemia and poor outcome in heterogeneous populations of critically ill patients $[3,4]$, especially among those with a history of

\footnotetext{
* Correspondence: ftaccone@ulb.ac.be

${ }^{9}$ Department of Intensive Care, Erasme Hospital, Free University of Brussels

(ULB), Route de Lennik, 808-1070 Brussels, Belgium

Full list of author information is available at the end of the article
}

cardiovascular disease [5]. However, the optimal threshold to trigger red blood cell (RBC) transfusion in ICU patients is not clearly established and may depend on other confounders related to the underlying disease or to patient characteristics.

It has been shown that tissue oxygen delivery $\left(\mathrm{DO}_{2}\right)$ is dependent on organ blood flow and arterial oxygen content, which includes the $\mathrm{Hb}$ concentration and its oxygen saturation [6]. Thus, during anemia, an increase in local blood flow or in oxygen extraction is necessary to maintain adequate $\mathrm{DO}_{2}$ and avoid tissue hypoxia. In healthy conditions, brain tissue has a high oxygen extraction rate, which may limit its ability to further compensate for reduced $\mathrm{DO}_{2}$ [7]. Thus, cerebral vasodilation 
and increased cerebral blood flow (CBF) are the main adaptive responses observed in the brain during anemia. In healthy volunteers, acute isovolemic anemia with $\mathrm{Hb}$ concentrations around $5 \mathrm{~g} / \mathrm{dl}$ was associated with cognitive deficits and impaired central processing, suggesting that maximal vasodilation had been achieved at these $\mathrm{Hb}$ concentrations and that no further increase in CBF could be obtained to compensate for reduced $\mathrm{DO}_{2}$ [8]. However, in acute brain injury, cerebral oxygen consumption may already be increased and cerebral vasodilation may be severely impaired, so that brain hypoxia could occur at higher $\mathrm{Hb}$ concentrations.

Several clinical studies have suggested that $\mathrm{Hb}$ concentrations less than $9 \mathrm{~g} / \mathrm{dl}$ are associated with tissue hypoxia, metabolic crises, and poor outcomes among patients with traumatic brain injury (TBI), subarachnoid hemorrhage $(\mathrm{SAH})$, or intracranial hemorrhage (ICH) [9-11]. However, in the same setting, RBC transfusion has been associated with poor neurological recovery $[12$, 13]. Thus, assessment of the risk/benefit ratio for transfusion is a key consideration in critically ill patients with acute brain injury [14]. Transfusion practice has moved toward more restrictive strategies in critically ill patients (i.e., to keep $\mathrm{Hb} \geq 7 \mathrm{~g} / \mathrm{dl}$ ) in recent years; however, more liberal targets (e.g., $\mathrm{Hb} \geq 9 \mathrm{~g} / \mathrm{dl}$ ) are recommended in patients with underlying cardiovascular disease [15]. Although this approach may also be logical in patients with acute brain injury, as was recommended in recent guidelines (i.e., to keep $\mathrm{Hb}$ between 8 and $10 \mathrm{~g} / \mathrm{dl}$ ) [2, $16]$, patients with acute brain injury were poorly represented in large clinical trials of RBC transfusion strategies, and further clinical investigation is needed in these patients.

To better understand the feasibility of such studies and how to develop future therapeutic protocols, it is important to assess transfusion practice of ICU physicians who manage patients with acute brain injury. Two surveys of transfusion practice in patients with TBI and SAH have been published $[17,18]$, but they were limited to cohorts of physicians in North America. Thus, the aim of this survey was to investigate, at a more global level, the management of anemia and RBC transfusion practice, including the $\mathrm{Hb}$ threshold for transfusion, in patients with acute brain injury.

\section{Methods}

This study was approved and endorsed by the European Society of Intensive Care Medicine (ESICM) Research Committee. No ethical approval was needed for the participating physicians.

\section{Study design and administration}

We conducted a web-based survey sent by email to all members of the ESICM, the Neurocritical Care Society, the Australian and New Zealand Intensive Care Society, the Società Italiana di Anestesia Analgesia Rianimazione e Terapia Intensiva, and the Brazilian Society of Critical Care (the questionnaire was not translated). The first email was sent on 21 May 2013, with two reminders sent 2 and 4 weeks thereafter, respectively. We did not specifically limit the survey to physicians working in academic institutions; our target sampling was intensivists who regularly care for patients with acute brain injury (i.e., neurointensivists, vascular neurosurgeons, neurologists) or with extensive interest and experience in the management of patients with acute brain injury. The survey was self-administered by the respondents, voluntary, and submitted online using a SurveyMonkey system (SurveyMonkey, San Mateo, CA, USA). No reimbursement was offered for questionnaire completion. All responses were anonymous.

\section{Survey development}

The survey was developed by two investigators (FST, MO) on the basis of a review of the relevant literature in this field. The questionnaire was presented at the NeuroIntensive Care Section of the ESICM meeting in October 2012 and sent by email to all participants of this section to obtain further input. A consensus was then achieved, and the final version of the survey was sent to the ESICM Research Committee, which gave its final endorsement after a peer review process (i.e., two reviewers).

The survey was constructed using 24 multiple-choice questions (Additional file 1: Appendix 1) to evaluate physicians' preferences for correcting anemia in patients with acute brain injury. We also recorded details of ICU and physician characteristics (i.e., country, specialty, position, years since completion of training, type of ICU, primary and secondary specialties, number of ICU beds, hospital size, and characteristics). We asked the respondents which $\mathrm{Hb}$ threshold they used to trigger $\mathrm{RBC}$ transfusion in patients with acute brain injury and whether the type of disease, patient characteristics, or specific conditions (e.g., increased intracranial pressure or vasospasm) would modify these thresholds. We also asked about the diagnosis and management of low iron levels and about the administration of erythropoietin. Finally, we asked clinicians about the potential risks and benefits of RBC transfusion in this setting and whether they believed a clinical trial should be conducted to specifically determine the optimal $\mathrm{Hb}$ threshold in this patient population. The survey was not specifically tested in a pilot cohort of potential respondents but underwent a peer review process within the ESICM Research Committee.

\section{Definitions}

We planned a priori to determine how transfusion practices might be influenced by geographical factors and 
categorized five world areas (Europe, North America, Central and South America, Asia/Africa, and Oceania). We also categorized $\mathrm{Hb}$ thresholds as a binary variable: less than $9 \mathrm{~g} / \mathrm{dl}$ or greater than or equal to $9 \mathrm{~g} / \mathrm{dl}$. We defined the factors that could influence RBC transfusion policy as noncerebral (e.g., active bleeding, coronary artery disease[CAD], low mixed venous oxygen saturation $\left[\mathrm{SvO}_{2}\right]$, age, lactate level greater than $2.5 \mathrm{mEq} / \mathrm{L}$ ) or cerebral (e.g., low brain tissue pressure levels $\left[\mathrm{PbtO}_{2}\right.$ less than $15 \mathrm{mmHg}$, delayed cerebral ischemia [DCI], data from other neuromonitoring tools [including electroencephalography, noninvasive cerebral oxygenation, transcranial Doppler], presence of intracranial hypertension, Glasgow Coma Scale score less than 9). Types of acute brain injury were separated as follows: TBI, SAH, ischemic stroke, $\mathrm{ICH}$, postneurosurgery, seizure and status epilepticus (SE), hypoxic-ischemic encephalopathy (HIE), central nervous system (CNS) infections, and noninfectious and autoimmune encephalitis.

\section{Statistical analysis}

Discrete variables are expressed as count (percent) and continuous variables as median (IQR or range, as indicated). Differences between study groups were assessed using a chi-square test, Fisher's exact test, KruskalWallis test, or Mann-Whitney $U$ test as appropriate. We performed multivariable logistic regression analyses to identify whether the following issues could be explained by the respondent's primary specialty (internal medicine, intensive care, anesthesiology, neurology, surgery, or pediatrics), the period since completion of training (years of practice), the type of ICU (medical, neuro-ICU, surgical), or institution (university, university-affiliated, non-university-affiliated) rather than the geographical difference itself: (a) the $\mathrm{Hb}$ threshold used to initiate RBC transfusion after acute brain injury, (b) use of noncerebral vs. cerebral factors to adjust the $\mathrm{Hb}$ threshold for transfusion, and (c) the concentration of $\mathrm{Hb}$ used to initiate RBC transfusion in the presence of one or more influencing factors. The collinearity between variables was checked by inspection of the correlation between them, by looking at the correlation matrix of the estimated parameters, and by looking at the change of parametric estimates and at their estimated standard errors. No instability of parametric estimates or an excessive increase of standard errors was observed during the analyses. A Hosmer-Lemeshow goodness-of-fit test was considered to assess model calibration (agreement between observed outcomes and predictions). Q-Q plots were drawn to check for normality in the residuals. Results are given as ORs and their 95\% CIs. Statistical analyses were performed using the IBM SPSS Statistics 24.0 for Windows NT software package (IBM, Armonk, NY, USA). All reported $p$ values are two-sided. A $p$ value less than 0.05 was considered to indicate statistical significance.

\section{Results}

Survey response and demographic characteristics

A total of 868 completed surveys were obtained from the five regions, $55 \%$ of which $(n=485)$ were from European ICUs (Additional file 1: Appendix 2 and Additional file 2: Figure S1). The countries with more respondents were Italy $(n=133)$, the United States $(n=129)$, the United Kingdom $(n=69)$, Switzerland $(n=58)$, and Australia $(n=$ 57). Almost one-fourth of respondents $(n=204$ [24\%]) had a specific certificate in neurocritical care (Table 1), with the highest proportion observed in North America. Most respondents $(n=729$ [84\%]) were specialists in anesthesiology or critical care (Table 1); a high proportion of respondents from North America said their primary specialty was neurology. Overall, only $20 \%$ of the respondents worked in a specialized neuro-ICU, but this proportion was significantly higher in North America than in other areas. Respondents from North America reported larger numbers of available ICU beds, more total patients, and more patients with acute brain injury admitted to the ICU on the day of the survey.

\section{Transfusion thresholds}

More than half the respondents $(n=466$ [54\%]) stated that an $\mathrm{Hb}$ threshold of 7 or $8 \mathrm{~g} / \mathrm{dl}$ to initiate RBC transfusion in patients with acute brain injury is used in their ICUs (Fig. 1, Additional file 2: Table S1). The lowest proportion of respondents who reported that they initiated $\mathrm{RBC}$ transfusion for $\mathrm{Hb}$ thresholds less than or equal to $8 \mathrm{~g} / \mathrm{dl}$ came from Europe and North America (both $49 \%$ ), whereas in Oceania, this strategy was used by $69 \%$ of respondents. When only respondents providing a specific $\mathrm{Hb}$ threshold were considered, Central and South American respondents used a lower $\mathrm{Hb}$ threshold than did those from Europe; similarly, respondents from Oceania used a lower threshold than those from Europe and Asia/Africa (Additional file 2: Figure S2).

A total of 435 (57\%) of 764 of the respondents reported that they used a different $\mathrm{Hb}$ threshold for RBC transfusion in patients with acute brain injury following TBI $(n=349)$, SAH $(n=279)$, ischemic stroke $(n=181)$, and HIE $(n=109)$, whereas only a few considered that a different transfusion policy was needed for patients with $\mathrm{ICH}(n=88)$, postneurosurgery $(n=88)$, seizure/SE $(n=$ $33)$, CNS infections $(n=27)$, or encephalitis $(n=18)$. Respondents more frequently replied that an $\mathrm{Hb}$ concentration of $9 \mathrm{~g} / \mathrm{dl}$ to initiate RBC transfusion was optimal in TBI (50\%), SAH (43\%), and ischemic stroke (38\%) than in the setting of other conditions (Fig. 2, Table 2; Additional file 2: Table S1). 
Table 1 Characteristics of respondents and their intensive care units

\begin{tabular}{|c|c|c|c|c|c|c|c|}
\hline & $\begin{array}{l}\text { Overall }(n= \\
868)\end{array}$ & $\begin{array}{l}\text { Europe }(n= \\
485)\end{array}$ & $\begin{array}{l}\text { North America ( } n \\
=140)\end{array}$ & $\begin{array}{l}\text { Central and South America } \\
(n=87)\end{array}$ & $\begin{array}{l}\text { Asia/Africa ( } n \\
=88)\end{array}$ & $\begin{array}{l}\text { Oceania }(n= \\
68)\end{array}$ & $\begin{array}{l}p \\
\text { Value }\end{array}$ \\
\hline Certificate & & & & & & & $<0.001$ \\
\hline Neurocritical care, $n(\%)$ & $77(9)$ & $11(3)$ & $59(42)$ & $4(5)$ & $3(3)$ & - & \\
\hline Critical care, $n(\%)$ & $532(61)$ & $321(66)$ & $32(23)$ & $63(72)$ & $61(69)$ & $55(81)$ & \\
\hline Both, $n(\%)$ & $127(15)$ & $75(15)$ & $31(22)$ & $12(14)$ & $5(6)$ & $4(5)$ & \\
\hline None, $n(\%)$ & $132(15)$ & $78(16)$ & $18(13)$ & $8(9)$ & $19(22)$ & $9(13)$ & \\
\hline Primary specialty & & & & & & & $<0.001$ \\
\hline Anesthesiology, $n$ (\%) & $234(27)$ & $186(38)$ & $7(5)$ & $7(8)$ & $32(36)$ & $2(3)$ & \\
\hline Intensive care, $n(\%)$ & $495(57)$ & $270(56)$ & $54(39)$ & $65(75)$ & $41(47)$ & $65(96)$ & \\
\hline Internal medicine, $n(\%)$ & $36(4)$ & $12(2)$ & $10(7)$ & $7(8)$ & $7(8)$ & - & \\
\hline Neurology, n (\%) & $70(8)$ & $5(1)$ & $57(41)$ & $5(6)$ & $3(3)$ & - & \\
\hline Pediatrics, $n(\%)$ & $12(1)$ & $9(2)$ & $1(1)$ & - & $1(1)$ & $1(1)$ & \\
\hline Surgery, $n(\%)$ & $21(2)$ & $3(1)$ & $11(8)$ & $3(3)$ & $4(5)$ & - & \\
\hline Years of practice & & & & & & & 0.07 \\
\hline$<5, n(\%)$ & $158(18)$ & $88(18)$ & $41(29)$ & $14(16)$ & $15(17)$ & - & \\
\hline $5-10, n(\%)$ & $241(28)$ & $132(27)$ & $33(24)$ & $23(26)$ & $35(40)$ & $18(26)$ & \\
\hline $11-15, n(\%)$ & $187(22)$ & $98(20)$ & $28(20)$ & $23(26)$ & $21(24)$ & $17(25)$ & \\
\hline $16-20, n(\%)$ & $117(13)$ & $71(15)$ & $14(10)$ & $10(11)$ & $7(8)$ & $15(22)$ & \\
\hline $21-25, n(\%)$ & $86(10)$ & $56(12)$ & $8(6)$ & $9(10)$ & $3(3)$ & $10(15)$ & \\
\hline$>25, n(\%)$ & $79(9)$ & $40(8)$ & $16(11)$ & $8(9)$ & $7(8)$ & $8(12)$ & \\
\hline Type of ICU & & & & & & & $<0.001$ \\
\hline Neuro-ICU, $n(\%)$ & $170(20)$ & $48(10)$ & $98(70)$ & $15(17)$ & $9(10)$ & - & \\
\hline Medical ICU, $n(\%)$ & $46(5)$ & $20(4)$ & - & $9(10)$ & $15(17)$ & $2(3)$ & \\
\hline Surgical ICU, $n(\%)$ & $75(9)$ & $54(11)$ & $7(5)$ & $3(3)$ & $11(13)$ & - & \\
\hline Mixed ICU, $n(\%)$ & $550(63)$ & $346(71)$ & $33(24)$ & $58(67)$ & $51(58)$ & $62(91)$ & \\
\hline Pediatric ICU, $n(\%)$ & $27(3)$ & $17(4)$ & $2(1)$ & $2(3)$ & $2(2)$ & $4(6)$ & \\
\hline Responsible for patients with $A B I$ in the ICU & & & & & & & $<0.001$ \\
\hline Anesthesiologist, $n(\%)$ & $76(9)$ & $67(14)$ & $1(1)$ & - & $8(9)$ & - & \\
\hline Intensivist, $n$ (\%) & $494(57)$ & $311(64)$ & $57(40)$ & $43(50)$ & $26(30)$ & $57(84)$ & \\
\hline Neurologist, $n(\%)$ & $13(1)$ & $2(1)$ & $5(4)$ & $2(2)$ & $4(5)$ & - & \\
\hline Neurosurgeon, $n(\%)$ & $26(3)$ & $4(1)$ & $7(5)$ & $5(6)$ & $10(11)$ & - & \\
\hline Mixed responsibility, $n(\%)$ & $259(30)$ & $101(21)$ & $70(50)$ & $37(43)$ & $40(45)$ & $11(17)$ & \\
\hline $\begin{array}{l}\text { Number of available ICU beds (on the day of } \\
\text { the survey) }\end{array}$ & 14 [10-22] & $12[8-18]$ & $20[16-27]$ & $13[10-20]$ & 15 [10-25] & 18 [12-23] & $<0.001$ \\
\hline Hospital size (beds) & & & & & & & $<0.001$ \\
\hline$<500, n(\%)$ & $345(40)$ & $175(36)$ & $40(29)$ & $65(75)$ & $39(44)$ & $26(38)$ & \\
\hline $500-750, n(\%)$ & $208(24)$ & $107(22)$ & $39(28)$ & $16(18)$ & $18(20)$ & $28(41)$ & \\
\hline $751-1000, n(\%)$ & $171(20)$ & $99(20)$ & $41(29)$ & $3(3)$ & $16(18)$ & $12(18)$ & \\
\hline$>1000, n(\%)$ & $144(17)$ & $104(21)$ & $20(14)$ & $3(3)$ & $15(17)$ & $2(3)$ & \\
\hline Type of institution & & & & & & & $<0.001$ \\
\hline University, n (\%) & $341(39)$ & $205(42)$ & $84(60)$ & $12(14)$ & $25(28)$ & $15(22)$ & \\
\hline University-affiliated, $n(\%)$ & $241(28)$ & $109(22)$ & $27(19)$ & $27(31)$ & $29(33)$ & $49(72)$ & \\
\hline Non-university-affiliated, $n(\%)$ & $286(33)$ & $171(35)$ & $29(21)$ & $48(55)$ & $34(39)$ & $4(6)$ & \\
\hline Patients on the day of survey, $n(\%)$ & $12[8-19]$ & $10[8-16]$ & 16 [12-20] & 12 [8-18] & $12[10-24]$ & $14[10-21]$ & $<0.001$ \\
\hline Patients with ABI on day of survey, $n(\%)$ & $3[2-6]$ & $3[1-5]$ & $10[4-13]$ & $4[2-6]$ & $4[2-8]$ & $3[2-4]$ & $<0.001$ \\
\hline
\end{tabular}




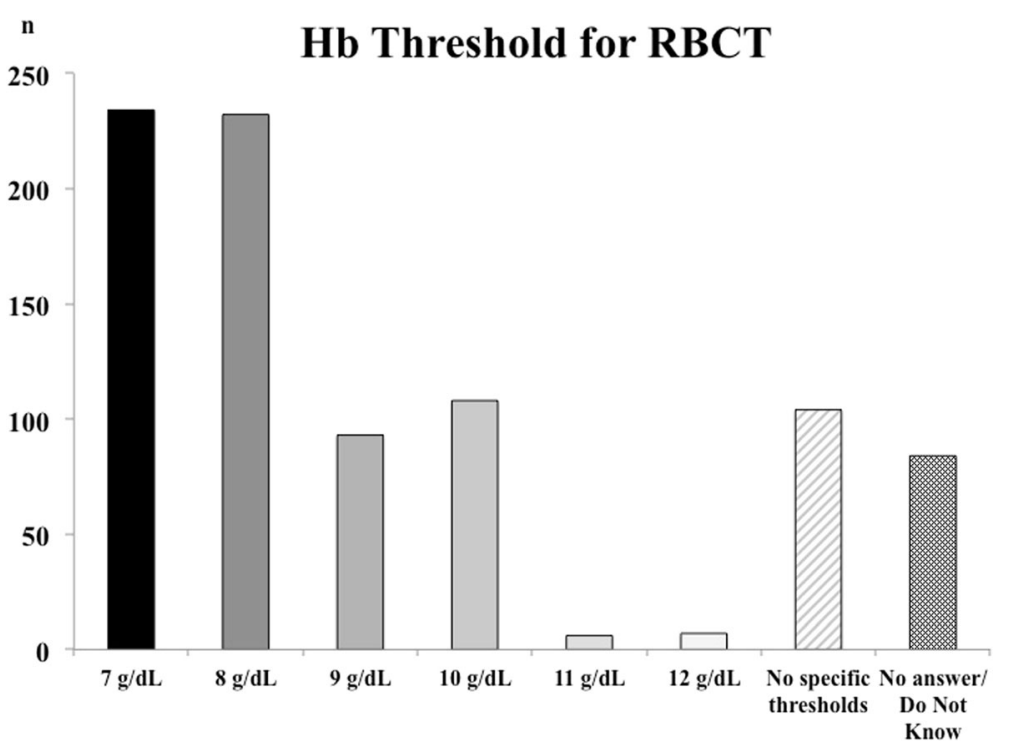

Fig. 1 Number of respondents $(n)$ for the recommended threshold of hemoglobin ( $\mathrm{Hb}$ ) used to initiate red blood cell transfusion (RBCT) in patients with acute brain injury

Overall, noncerebral factors, such as known CAD $(n=$ 474), active bleeding $(n=462)$, and low $\mathrm{SvO}_{2}(n=393)$, were more often reported to influence the $\mathrm{Hb}$ threshold for transfusion than cerebral factors (Additional file 2: Table S1 and Figure S3). However, cerebral factors represented $40 \%$ of the potential determinants of $\mathrm{RBC}$ transfusion threshold change in North America, whereas this proportion was significantly lower on other continents, with the lowest value being in Oceania (17\%) (Additional file 2: Figure S4). In the presence of any of

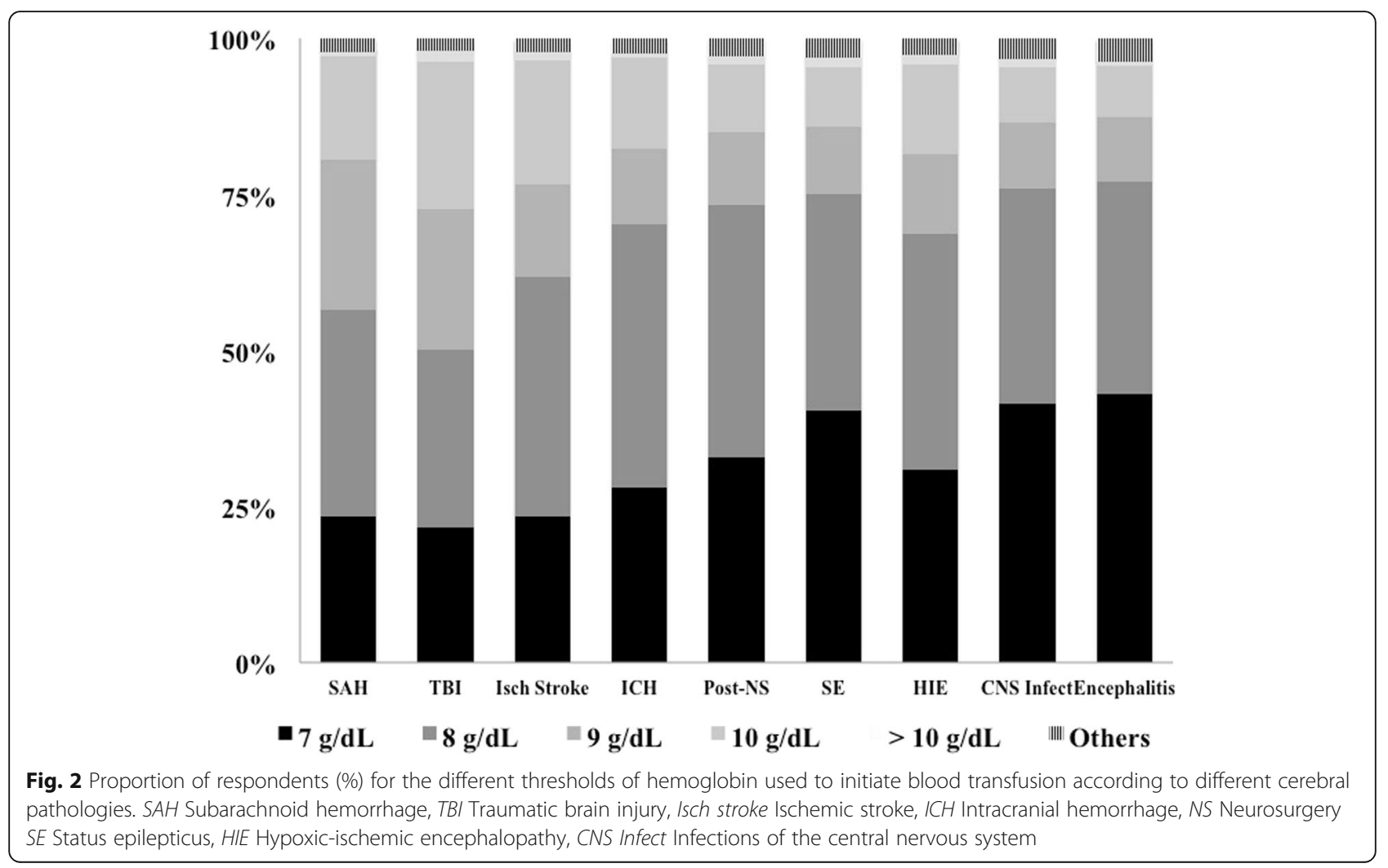


Table 2 Optimal hemoglobin threshold that respondents would use to initiate transfusion for different forms of acute brain injury

\begin{tabular}{|c|c|c|c|c|c|c|c|c|c|}
\hline $\begin{array}{l}\text { Optimal } \mathrm{Hb} \text { threshold to } \\
\text { initiate RBCT }\end{array}$ & $\begin{array}{l}\text { SAH }(n= \\
698)\end{array}$ & $\begin{array}{l}\text { TBI }(n= \\
704)\end{array}$ & $\begin{array}{l}\text { IS }(n= \\
694)\end{array}$ & $\begin{array}{l}\mathrm{ICH}(n= \\
693)\end{array}$ & $\begin{array}{l}\text { NS }(n= \\
655)\end{array}$ & $\begin{array}{l}\text { Seizure/SE }(n= \\
596)\end{array}$ & $\begin{array}{l}\text { HIE }(n= \\
659)\end{array}$ & $\begin{array}{l}\text { CNS Inf }(n= \\
594)\end{array}$ & $\begin{array}{l}\text { Enceph }(n= \\
\text { 582) }\end{array}$ \\
\hline $7 \mathrm{~g} / \mathrm{dl}, n(\%)$ & $163(23)$ & $152(22)$ & $163(24)$ & $195(28)$ & 216 (33) & $241(40)$ & $203(31)$ & $247(42)$ & $250(43)$ \\
\hline $8 \mathrm{~g} / \mathrm{dl}, n(\%)$ & $232(33)$ & $200(28)$ & $266(38)$ & $291(42)$ & $264(40)$ & $206(35)$ & $250(38)$ & $204(34)$ & $199(34)$ \\
\hline $9 \mathrm{~g} / \mathrm{dl}, n(\%)$ & $167(24)$ & $159(23)$ & $103(15)$ & $85(12)$ & $77(12)$ & $65(11)$ & $84(13)$ & $63(11)$ & $60(10)$ \\
\hline $10 \mathrm{~g} / \mathrm{dl}, \mathrm{n}(\%)$ & $116(17)$ & $167(24)$ & $138(20)$ & $100(14)$ & $71(11)$ & $57(10)$ & $94(14)$ & $52(9)$ & $47(8)$ \\
\hline$>10 \mathrm{~g} / \mathrm{dl}, n(\%)$ & $5(1)$ & $12(2)$ & $9(1)$ & $5(1)$ & $8(1)$ & $9(2)$ & $11(2)$ & $8(1)$ & $4(1)$ \\
\hline Others, n (\%) & $15(2)$ & $14(2)$ & $15(2)$ & $17(2)$ & $19(3)$ & $18(3)$ & $17(3)$ & $20(3)$ & $22(4)$ \\
\hline
\end{tabular}

Abbreviations: SAH Subarachnoid hemorrhage, TBI Traumatic brain injury, IS Ischemic stroke, ICH Intracranial hemorrhage, SE Status epilepticus, HIE Hypoxicischemic encephalopathy, CNS Infect Infections of the central nervous system, Enceph Encephalitis, Hb Hemoglobin, RBCT Red blood cell transfusion $p<0.001$ for trend among groups

these factors, 497 (57\%) of 868 of respondents said they would increase the $\mathrm{Hb}$ threshold to initiate $\mathrm{RBC}$ transfusion to 9 or $10 \mathrm{~g} / \mathrm{dl}$ (Additional file 2: Table S1and Figure S5). When only respondents providing a specific $\mathrm{Hb}$ threshold were considered, the $\mathrm{Hb}$ threshold to initiate transfusion was significantly higher when one or more influencing factors was present than when they were not (Fig. 3).

The main reason reported for giving a transfusion to a patient with acute brain injury was the potential increase in $\mathrm{DO}_{2}$ to ischemic regions $(n=625$ [72\%]) (Additional file 2: Table S1). Thirty percent of respondents said they would check the length of RBC storage before transfusion, but only one-third of these respondents would limit the administration of "old" RBC units. Only 76 of the respondents reported the maximum duration of $\mathrm{RBC}$ storage allowed for transfusion (median 15; range 2-150). Only $20 \%$ ( $n=176)$ of respondents would give non-leukocytedepleted RBC units to patients with acute brain injury.

The main reasons given for limiting transfusions in all patients with acute brain injury were the risk of transfusion-related acute lung injury (18\%), risk of infection (17\%), and altered immune response (14\%) (Additional file 2: Table S1). More than $60 \%$ of respondents

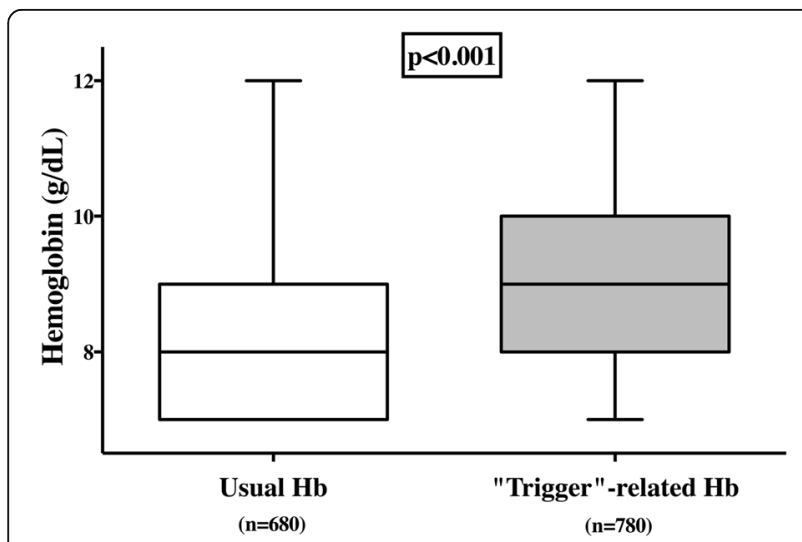

Fig. 3 Median normal hemoglobin $(\mathrm{Hb})$ values and altered values in the presence of trigger factors
( $n=523)$ thought that a randomized clinical trial (RCT) comparing a restrictive and a liberal transfusion strategy was necessary in the setting of acute brain injury (Additional file 2: Figure S6); 306 (59\%) respondents thought this study should compare two different $\mathrm{Hb}$ thresholds for initiating transfusion, and 217 (41\%) thought it should compare a restrictive strategy with a strategy guided by neuromonitoring (e.g., $\mathrm{PbtO}_{2}$ or noninvasive cerebral oxygen saturation). The forms of acute brain injury that should be included in this study were, in particular, SAH $(n=592)$ and TBI $(n=560)$, whereas the need for such a study was considered less relevant for ischemic stroke $(n=354)$ or hemorrhagic stroke $(n=275)$, HIE $(n=211)$, postneurosurgery patients $(n=133)$, seizure/SE $(n=79)$, CNS infection $(n=79)$, or encephalitis $(n=66)$.

\section{Other issues}

Few respondents measured iron levels before RBC transfusion in their clinical practice, except in North America and Asia/Africa, where more than $10 \%$ of those who responded stated that iron levels were checked in more than $50 \%$ of patients (i.e., frequently or often) (Additional file 2: Table S1). Three hundred three (41\%) of 738 respondents (130 did not answer this question) gave iron supplements to patients with anemia who had acute brain injury (always, $n=17$; only if the ICU length of stay was longer than 1 week, $n=43$; only if iron levels were reduced, $n=200$; only if patients received more than 8 RBC units, $n=14$; only if no signs of infection, $n$ $=29$ ). Nearly $40 \%$ of respondents would frequently or often check for the presence of chronic anemia in patients with acute brain injury before initiating transfusion, with similar response rates across regions (Additional file 2: Table S1). More than $80 \%$ of respondents said they did not use erythropoietin (EPO) in patients with acute brain injury (Additional file 2: Table S1); among those who would give such therapy, EPO was used more in TBI $(n=83)$ and SAH $(n=62)$ than in other diseases (HIE, $n=46$; ischemic stroke, $n=39$; after neurosurgery, $n=25$; ICH, $n=21$; CNS infection or encephalitis, $n=18$ each; seizure and/or SE, $n=10$ ). 


\section{Multivariable analysis}

In multivariable analysis, the selection of $\mathrm{Hb}$ threshold to initiate RBC transfusion was significantly determined by regions (Asia/Africa and Oceania were significantly associated with a more conservative threshold when compared with Europe) and physicians' characteristics (anesthesiologists were significantly more likely to use a liberal $\mathrm{Hb}$ threshold than were intensivists or physicians in intensivist-run ICUs) (Additional file 2: Table S2). Neurologists were more likely to state that noncerebral factors influenced their decision to transfuse than were intensivists, as were physicians working in large hospitals (750-1000 beds) compared with smaller hospitals.

Physicians working in ICUs in which patients with acute brain injuries were managed by a neurosurgeon more frequently used cerebral factors to trigger RBC transfusion than did physicians working in intensivistrun ICUs. The use of conservative transfusion policies, even if a trigger factor was present, was more common in physicians with more than 25 years of practice than in those with less than 5 years of practice and by physicians working in ICUs in which patients with acute brain injury were managed by a neurosurgeon compared with intensivist-run ICUs. Finally, physicians who said they used cerebral factors to alter transfusion thresholds were more likely to suggest that a randomized RCT should be performed to compare a restrictive strategy with a strategy guided by neuromonitoring rather than an RCT comparing two $\mathrm{Hb}$ thresholds.

\section{Discussion}

This worldwide survey is the largest to provide data on the approach of physicians to anemia management and $\mathrm{Hb}$ thresholds for RBC transfusion in patients with acute brain injury. More than half of the respondents stated that they used an $\mathrm{Hb}$ threshold of 7-8 $\mathrm{g} / \mathrm{dl}$ to initiate $\mathrm{RBC}$ transfusion after acute brain injury. A lower threshold for transfusion was observed in Africa/Asia and Oceania than in Europe. However, most respondents stated that they would increase the Hb trigger threshold in the presence of various factors, in particular CAD, active bleeding, and low $\mathrm{SvO}_{2}$. Most respondents said they felt an RCT was needed to compare different transfusion strategies in this patient population, in particular after SAH and TBI. Respondents' characteristics that influenced transfusion policies in this setting included their origin, their background, and their experience, with the most liberal approaches used by respondents from Europe and North America, by anesthesiologists and neurologists/neurosurgeons, and by those with less than 5 years in practice.

Only two other surveys have evaluated transfusion practice in patients with acute brain injury. In the first study, Sena et al. [17] evaluated responses of 312 physicians, including trauma surgeons, neurosurgeons, and intensivists from level I trauma centers in the United States. The authors used two clinical scenarios, focusing only on TBI. Neurosurgeons reported the highest $\mathrm{Hb}$ thresholds for initiating $\mathrm{RBC}$ transfusion compared with trauma surgeons and intensivists in patients with normal ( 8.3 vs. 7.5 vs. $7.5 \mathrm{~g} / \mathrm{dl}$, respectively) and elevated ( 8.9 vs. 8.0 vs. $8.4 \mathrm{~g} / \mathrm{dl}$, respectively) intracranial pressure. Interestingly, fewer neurosurgeons than other physicians reported that they used systemic and cerebral factors to influence the decision to transfuse. In a second study, Kramer et al. [18] performed a survey of 282 academic neurointensivists, neurosurgeons, and multidisciplinary intensivists from the United States and Canada to evaluate transfusion policies for patients with $\mathrm{SAH}$. The mean $\mathrm{Hb}$ concentration used to initiate $\mathrm{RBC}$ transfusion was higher in low-grade patients $(8.2 \mathrm{~g} / \mathrm{dl})$ and in those with DCI $(8.6 \mathrm{~g} / \mathrm{dl})$, with large variability in the proposed ranges. Again, neurosurgeons expressed the highest minimum $\mathrm{Hb}$ goals compared with other physicians. Respondents were more likely to transfuse patients with low $\mathrm{PbtO}_{2}$ values and high brain lactateto-pyruvate ratios. Similarly, we also found that most of the respondents used an $\mathrm{Hb}$ threshold of 7-8 g/dl to initiate RBC transfusion in patients with acute brain injury, although nearly $60 \%$ of these respondents used a higher threshold in patients with TBI, SAH, and ischemic stroke.

Nevertheless, in our study, we made some interesting observations that were not reported in the previous surveys. First, $\mathrm{Hb}$ thresholds were more liberal among anesthesiologists than among intensivists. This may appear to be in contrast to recent guidelines from the American Society of Anesthesiologists suggesting the need for restrictive transfusion criteria to minimize RBC use with no additional risks for poor outcome or cardiac, neurological, or pulmonary complications [19]. Differences in practice between these two groups of physicians may explain these findings, with more than half of transfusions given by anesthesiologists partially initiated as a result of a physiological trigger (e.g., hypotension, tachycardia, preexisting anemia) rather than the absolute value of $\mathrm{Hb}$ [20]. Moreover, one study also showed that, in 48,086 surgical patients at a tertiary U.S. academic medical center, the target $\mathrm{Hb}$ value after transfusion ordered by an anesthesiologist was $11.7 \pm 1.3 \mathrm{~g} / \mathrm{dl}$ [21]. Second, previous surveys have been focused only on physicians in North America, whereas we report that a conservative (i.e., $7-8 \mathrm{~g} / \mathrm{dl}$ ) threshold of $\mathrm{Hb}$ was more often used in Asia/Africa and Oceania than in Europe to initiate transfusion. The lower threshold used in African and Asian countries may be due to limited resources and less blood availability, as well as to shortage of other supplies (e.g., bottles, bags) and greater risk of blood contamination 
[22]. The differences between Europe and Oceania may be explained by national and statewide initiatives in Australia/New Zealand to encourage implementation of patient blood management programs as a cost-effective standard of care in their public health system, whereas this approach is not entirely integrated into routine management in Europe [23, 24].

In this survey, we observed that many clinicians did not initiate RBC transfusion at a fixed $\mathrm{Hb}$ threshold, but adjusted their practice according to the presence of other factors. In particular, compared with intensivists, neurologists more frequently used noncerebral trigger factors, and neurosurgeons used more frequently used cerebral factors. The presence of systemic factors such as low $\mathrm{SvO}_{2}$ values has been widely used to trigger $\mathrm{RBC}$ transfusion in critically ill patients with sepsis [25]. RBC transfusion may also improve microvascular abnormalities associated with sepsis or may contribute to improved tissue oxygenation in patients with high lactate levels [26, 27]. Similarly, Oddo et al. [10] showed that only the combination of low $\mathrm{Hb}$ concentrations with reduced $\mathrm{PbtO}_{2}$ values negatively affected the outcome of patients with TBI. Thus, decisions regarding when to transfuse patients with acute brain injury remain difficult and should be titrated on an individual patient basis. Biomarkers of impaired systemic or tissue $\mathrm{DO}_{2}$ may help identify patients who are most likely to benefit from RBC transfusion in this setting. Heterogeneity in clinical practice among physicians with different backgrounds also suggests the need to better evaluate and identify which biomarkers could be used in this context.

More than $60 \%$ of respondents thought that an RCT comparing a restrictive and a liberal transfusion strategy was needed, in particular in patients with SAH and TBI. Interestingly, whereas $40 \%$ indicated that one group should be guided by neuromonitoring, only $13 \%$ of all respondents stated that neuromonitoring influenced their RBC transfusion policy and that transfusions were guided mainly by noncerebral events. This finding underlines that the availability of cerebral trigger factors as a tool to guide transfusion policy may be logistically difficult because these tools are not widely available. Also, the optimal threshold to initiate RBC transfusion in critically ill patients remains unclear, and many physicians still use predefined $\mathrm{Hb}$ values in their practice. Finally, it is also possible that the limited options provided in the survey format prevented respondents from providing other alternatives to an RCT comparing restrictive vs. liberal transfusion. Although the willingness to evaluate transfusion practices in the context of a randomized trial has also been suggested in previous surveys $[17,18]$, it remains unclear which threshold could accurately define a restrictive or a liberal approach. Current guidelines for $\mathrm{RBC}$ transfusion in the critically ill suggest initiating transfusion when the $\mathrm{Hb}$ is less than $7 \mathrm{~g} / \mathrm{dl}$ because higher thresholds do not provide additional benefit [28] Nevertheless, most practitioners would probably adopt a higher transfusion $\mathrm{Hb}$ threshold in patients with acute coronary syndrome, as well as in those at risk of secondary brain injury, such as patients with SAH with DCI or in patients with severe TBI $[11,29,30]$. However, it remains unclear whether using $\mathrm{RBC}$ transfusion to increase $\mathrm{Hb}$ concentrations to $9-11 \mathrm{~g} / \mathrm{dl}$ is a logical therapeutic decision to improve cerebral oxygenation and neurological recovery in these patients. Indeed, in patients with TBI, the increase in $\mathrm{PbtO}_{2}$ after $\mathrm{RBC}$ transfusion was generally limited [31, 32]. In patients with low-grade SAH, each $1.0 \mathrm{~g} / \mathrm{dl}$ increase in Hb concentration after transfusion was associated with an increase of $1.4 \mathrm{mmHg}$ in $\mathrm{PbtO}_{2}$, without significant effects on cerebral metabolism [33]. In another study, RBC transfusion resulted in a significant improvement in cerebral $\mathrm{DO}_{2}$, in particular in those cerebral territories with the lowest baseline $\mathrm{DO}_{2}$, and these effects were more significant than those produced by fluid expansion or vasopressors [34, 35].

Although we observed some differences in Hb thresholds and RBC transfusion practices across regions and specialties, we could not determine from our survey whether this was due to discrepancies in local protocols, lack of compliance with general recommendations, or other factors that we did not investigate. For example, we showed that working in large hospitals (for the use of noncerebral triggers) and a greater degree of seniority (for the use of a conservative threshold) may influence the decision to transfuse. Whether these observations reflect a different familiarity with published literature on these issues or just personal practice is difficult to determine.

This survey has several limitations that need to be acknowledged. First, the validity of the survey depends on a high response rate among target physicians. Because the questionnaire was distributed using email addresses of members of different medical societies, we could not determine the potential denominator, which may have resulted in an underpowered analysis. The total number of potential respondents (i.e., considering the members of participating critical care societies; a list of respondents per countries is provided in Additional file 1: Appendix 2) probably exceeded 15,000 people, and this might significantly limit the external validity/ generalizability of our findings. We did not specifically contact only physicians who were experts in neurocritical care, as was the case in previous surveys $[17,18]$; we also allowed other physicians working in general or mixed ICUs treating these patients to respond, and this may provide a broader picture of the general management of these patients who are admitted to 
nonspecialized ICUs in many countries. Second, survey development and testing should follow a process of item generation through a process of a systematic review; item reduction; pretesting; and pilot testing for clinical sensibility, reliability, and validity [36]. Our survey was based on a consensus within experts in the NeuroIntensive Care Section of the ESICM, and the preparation process might have affected comprehensiveness, clarity, and face validity as well as respondents' interpretation of questions. Third, as is true for all surveys, the responses do not necessarily reflect local practice but personal opinions of the strategy used to manage $\mathrm{RBC}$ transfusion in this setting. A prospective audit collecting data on this topic would be welcome to provide more real-world data for this therapeutic intervention. Fourth, we had few respondents from Africa and needed to consider Asia and Africa as a single group, although practices may be different in these two areas. Fifth, our survey was conducted before the publication of a recent U.S. study evaluating RBC transfusion management in patients with TBI [37], which showed no differences between a liberal $(\mathrm{Hb}$ less than $10 \mathrm{~g} / \mathrm{dl})$ and a restrictive (Hb less than $7 \mathrm{~g} / \mathrm{dl}$ ) transfusion strategy. It is impossible to know whether these results would have influenced the responses in our survey. Finally, because the survey was conducted anonymously, we could not control whether several respondents worked at the same center, which may have influenced the variability and generalizability of the results.

\section{Conclusions}

In this large survey, most physicians reported using a conservative $\mathrm{Hb}(7-8 \mathrm{~g} / \mathrm{dl})$ to initiate $\mathrm{RBC}$ transfusion in patients with acute brain injury, although half of them would use a higher $\mathrm{Hb}$ threshold after TBI, $\mathrm{SAH}$, and ischemic stroke. Both systemic and cerebral factors may influence the choice of $\mathrm{Hb}$ threshold used for transfusion in these patients. Several differences according to physician specialty and regional areas were identified. An RCT comparing two different $\mathrm{Hb}$ thresholds for RBC transfusion in this setting would be more than welcome. Whether the optimal trial design should rely on predefined $\mathrm{Hb}$ values to separate the study groups or use specific thresholds (either cerebral or systemic) remains to be further clarified.

\section{Additional files}

Additional file 1: Appendix 1. Survey questionnaire. Appendix 2: Number of respondents per countries. (DOCX $37 \mathrm{~kb}$ )

Additional file 2: Table S1. Transfusion policies among respondents. Table S2. Multivariable logistic regression analyses assessing associations between respondent characteristics and various transfusion policies for patients with acute brain injury (ABI). Figure S1. Regional distribution of respondents across continents. Figure S2. Median threshold of hemoglobin $(\mathrm{Hb})$ recommended to initiate blood transfusion in patients with $A B I$ in different geographic regions. Figure S3. Number of respondents reporting that different trigger factors ( $n$ ) would influence their decision to initiate blood transfusion in patients with ABI. Figure S4. Relative proportions of noncerebral and cerebral trigger factors (\%) used to initiate blood transfusion in patients with $A B I$, according to geographic region. Figure S5. Number of respondents ( $n$ ) stating they would use a new threshold of hemoglobin $(\mathrm{Hb})$ to initiate blood transfusion in patients with $A B I$ in the presence of a trigger factor. Figure S6. Number of respondents $(n)$ agreeing with the need for a randomized clinical trial $(\mathrm{RCT})$ in patients with anemia from patients with $\mathrm{ABI}$. (DOCX $884 \mathrm{~kb})$

\section{Acknowledgements}

This survey was endorsed by the European Society of Intensive Care Medicine (ESICM).

Funding

No funding was received for this study.

\section{Availability of data and material}

The datasets used and/or analyzed during the present study are available from the corresponding author on reasonable request.

\section{Authors' contributions}

FST, GC, and MO conceived of the study protocol. FST, GC, and MO participated in the design and coordination of the study. JIS, MA, JL, and RB participated in data interpretation. RB and FST carried out the literature search. RB, FST, and MO drafted the manuscript. GC, JIS, JL, and MA revised the manuscript. All authors read and approved the final manuscript.

\section{Competing interests}

The authors declare that they have no competing interests.

\section{Consent for publication}

All authors approved the final version of the manuscript and consented to its publication.

Ethics approval and consent to participate

Not applicable.

\section{Publisher's Note}

Springer Nature remains neutral with regard to jurisdictional claims in published maps and institutional affiliations.

\section{Author details}

${ }^{1}$ Department of Anesthesiology and Surgical Intensive Care, Hospital Clinic Universitari, Valencia, Spain. ${ }^{2}$ Department of Intensive Care Medicine, Centre Hospitalier Universitaire Vaudois (CHUV), Lausanne University Hospital, 1011 Lausanne, Switzerland. ${ }^{3}$ Division of Vascular Neurology and Neurocritical Care, Department of Neurology, Baylor College of Medicine, Catholic Health Initiatives (CHI) Baylor St. Luke's-Baylor St. Luke's Medical Center, Houston, TX, USA. ${ }^{4}$ Department of Anesthesiology and Intensive Care Medicine, Catholic University - Fondazione Policlinico Agostino Gemelli University Hospital, Rome, Italy. ${ }^{5}$ ntensive Care Services, Royal Brisbane and Women's Hospital, Herston, Australia. ${ }^{6}$ Burns Trauma Critical Care Research Centre, University of Queensland, Herston, Australia. ${ }^{7}$ School of Medicine and Surgery, University of Milano-Bicocca, Monza, Italy. ${ }^{8}$ Neurointensive Care, San Gerardo Hospital, Azienda Socio Sanitaria Territoriale (ASST) of Monza, Monza, Italy. ${ }^{9}$ Department of Intensive Care, Erasme Hospital, Free University of Brussels (ULB), Route de Lennik, 808-1070 Brussels, Belgium.

Received: 20 February 2017 Accepted: 31 May 2017

Published online: 17 June 2017

\section{References}

1. Walsh TS, Lee RJ, Maciver CR, Garrioch M, Mackirdy F, Binning AR, et al. Anemia during and at discharge from intensive care: the impact of restrictive blood transfusion practice. Intensive Care Med. 2006;32:100-9. 
2. Retter A, Wyncoll D, Pearse R, Carson D, McKechnie S, Stanworth S, et al. Guidelines on the management of anaemia and red cell transfusion in adult critically ill patients. Br J Haematol. 2013;160:445-64.

3. Hébert PC, Wells G, Blajchman MA, Marshall J, Martin C, Pagliarello G, et al. A multicenter, randomized, controlled clinical trial of transfusion requirements in critical care. N Engl J Med. 1999;340:409-17. A published erratum appears in N Engl J Med. 1999;340:1056.

4. Wu WC, Schifftner TL, Henderson WG, Eaton CB, Poses RM, Uttley G, et al. Preoperative hematocrit levels and postoperative outcomes in older patients undergoing noncardiac surgery. JAMA. 2007;297:2481-8.

5. Kulier A, Levin J, Moser R, Rumpold-Seitlinger G, Tudor IC, Snyder-Ramos SA et al. Impact of preoperative anemia on outcome in patients undergoing coronary artery bypass graft surgery. Circulation. 2007;116:471-9.

6. Hare GM, Tsui AK, Ozawa S, Shander A. Anaemia: can we define haemoglobin thresholds for impaired oxygen homeostasis and suggest new strategies for treatment? Best Pract Res Clin Anaesthesiol. 2013;27:85-98.

7. Safaeian N, David T. A computational model of oxygen transport in the cerebrocapillary levels for normal and pathologic brain function. J Cereb Blood Flow Metab. 2013;33:1633-41.

8. Weiskopf RB, Toy P, Hopf HW, Feiner J, Finlay HE, Takahashi M, et al. Acute isovolemic anemia impairs central processing as determined by P300 latency. Clin Neurophysiol. 2005;116:1028-32.

9. Pendem S, Rana S, Manno MG, Gajic O. A review of red cell transfusion in the neurological intensive care unit. Neurocrit Care. 2006;4:63-7.

10. Oddo M, Levine JM, Kumar M, Iglesias K, Frangos S, Maloney-Wilensky E, et al. Anemia and brain oxygen after severe traumatic brain injury. Intensive Care Med. 2012;38:1497-504.

11. Kramer AH, Zygun DA, Bleck TP, Dumont AS, Kassell NF, Nathan B. Relationship between hemoglobin concentrations and outcomes across subgroups of patients with aneurysmal subarachnoid hemorrhage. Neurocrit Care. 2009;10:157-65.

12. George ME, Skarda DE, Watts CR, Pham HD, Beilman GJ. Aggressive red blood cell transfusion: no association with improved outcomes for victims of isolated traumatic brain injury. Neurocrit Care. 2008;8:337-43.

13. Warner MA, O'Keeffe T, Bhavsar P, Shringer R, Moore C, Harper C, et al. Transfusions and long-term functional outcomes in traumatic brain injury. J Neurosurg. 2010;113:539-46.

14. Leroux P. Haemoglobin management in acute brain injury. Curr Opin Crit Care. 2013;19:83-91.

15. Hebert PC, Wells G, Tweeddale M, Martin C, Marshall J, Pham B, et al. Does transfusion practice affect mortality in critically ill patients? Transfusion Requirements in Critical Care (TRICC) Investigators and the Canadian Critical Care Trials Group. Am J Respir Crit Care Med. 1997;155:1618-23.

16. Napolitano LM, Kurek S, Luchette FA, Corwin HL, Barie PS, Tisherman SA, et al. Clinical practice guideline: red blood cell transfusion in adult trauma and critical care. Crit Care Med. 2009;37:3124-57. A published erratum appears in Crit Care Med. 2010;38:1621.

17. Sena MJ, Rivers RM, Muizelaar JP, Battistella FD, Utter GH. Transfusion practices for acute traumatic brain injury: a survey of physicians at US trauma centers. Intensive Care Med. 2009;35:480-8.

18. Kramer AH, Diringer MN, Suarez Jl, Naidech AM, Macdonald LR, Le Roux PD. Red blood cell transfusion in patients with subarachnoid hemorrhage: a multidisciplinary North American survey. Crit Care. 2011;15:R30.

19. American Society of Anesthesiologists Task Force on Perioperative Blood Management. Practice guidelines for perioperative blood management: an updated report by the American Society of Anesthesiologists Task Force on Perioperative Blood Management. Anesthesiology. 2015;122:241-75.

20. Meier J, Filipescu D, Kozek-Langenecker S, Llau Pitarch J, Mallett S, Martus P, et al. Intraoperative transfusion practices in Europe. Br J Anaesth. 2016;116:255-61.

21. Frank SM, Savage WJ, Rothschild JA, Rivers RJ, Ness PM, Paul SL, et al. Variability in blood and blood component utilization as assessed by an anesthesia information management system. Anesthesiology. 2012;117: 99-106.

22. Schneider WH. History of blood transfusion in sub-Saharan Africa. Transfus Med Rev. 2013;27:21-8.

23. Theusinger OM, Felix C, Spahn DR. Strategies to reduce the use of blood products: a European perspective. Curr Opin Anaesthesiol. 2012;25:59-65.

24. Hofmann A, Farmer S, Towler SC. Strategies to preempt and reduce the use of blood products: an Australian perspective. Curr Opin Anaesthesiol. 2012; 25:66-73.
25. Rivers E, Nguyen B, Havstad S, Ressler J, Muzzin A, Knoblich B, et al. Early goal-directed therapy in the treatment of severe sepsis and septic shock. $\mathrm{N}$ Engl J Med. 2001;345:1368-77.

26. Sakr Y, Chierego M, Piagnerelli M, Verdant C, Dubois MJ, Koch M, et al. Microvascular response to red blood cell transfusion in patients with severe sepsis. Crit Care Med. 2007;35:1639-44.

27. Sadaka F, Aggu-Sher R, Krause K, O'Brien J, Armbrecht ES, Taylor RW. The effect of red blood cell transfusion on tissue oxygenation and microcirculation in severe septic patients. Ann Intensive Care. 2011;1:46.

28. Carson JL, Guyatt G, Heddle NM, Grossman BJ, Cohn CS, Fung MK, et al. Clinical practice guidelines from the AABB: red blood cell transfusion thresholds and storage. JAMA. 2016;316:2025-35.

29. Sekhon MS, McLean N, Henderson WR, Chittock DR, Griesdale DE. Association of hemoglobin concentration and mortality in critically ill patients with severe traumatic brain injury. Crit Care. 2012;16:R128.

30. Kramer AH, Gurka MJ, Nathan B, Dumont AS, Kassell NF, Bleck TP. Complications associated with anemia and blood transfusion in patients with aneurysmal subarachnoid hemorrhage. Crit Care Med. 2008;36:2070-5.

31. Smith MJ, Stiefel MF, Magge S, Frangos S, Bloom S, Gracias V, et al. Packed red blood cell transfusion increases local cerebral oxygenation. Crit Care Med. 2005;33:1104-8.

32. Zygun DA, Nortje J, Hutchinson PJ, Timofeev I, Menon DK, Gupta AK. The effect of red blood cell transfusion on cerebral oxygenation and metabolism after severe traumatic brain injury. Crit Care Med. 2009;37:1074-8.

33. Kurtz P, Helbok R, Claassen J, Schmidt JM, Fernandez L, Stuart RM, et al. The effect of packed red blood cell transfusion on cerebral oxygenation and metabolism after subarachnoid hemorrhage. Neurocrit Care. 2016;24:118-21.

34. Dhar R, Zazulia AR, Videen TO, Zipfel GJ, Derdeyn CP, Diringer MN. Red blood cell transfusion increases cerebral oxygen delivery in anemic patients with subarachnoid hemorrhage. Stroke. 2009;40:3039-44.

35. Dhar R, Scalfani MT, Zazulia AR, Videen TO, Derdeyn CP, Diringer MN. Comparison of induced hypertension, fluid bolus, and blood transfusion to augment cerebral oxygen delivery after subarachnoid hemorrhage. J Neurosurg. 2012;116:648-56.

36. Burns KE, Duffett $M$, Kho ME, Meade MO, Adhikari NK, Sinuff $T$, et al. A guide for the design and conduct of self-administered surveys of clinicians. CMAJ. 2008;179:245-52.

37. Robertson CS, Hannay HJ, Yamal JM, Gopinath S, Goodman JC, Tilley BC, et al. Effect of erythropoietin and transfusion threshold on neurological recovery after traumatic brain injury: a randomized clinical trial. JAMA. 2014; 312:36-47.

\section{Submit your next manuscript to BioMed Central and we will help you at every step:}

- We accept pre-submission inquiries

- Our selector tool helps you to find the most relevant journal

- We provide round the clock customer support

- Convenient online submission

- Thorough peer review

- Inclusion in PubMed and all major indexing services

- Maximum visibility for your research

Submit your manuscript at www.biomedcentral.com/submit 